\section{Ecoturismo: Discurso, Desejo e Realidade}

\section{Zysman Neiman \\ Rita Mendonça ${ }^{2}$}

RESUMO: Discute aspectos relativos à relação entre ser humano e natureza no mundo contemporâneo e as póssibilidades de desenvolvimento de novos valores e atitudes a partir do trabalho com ecoturismo em unidades de conservação. O distanciamento entre a intenção e as práticas corriqueiras, comuns nessecampode atividade, é questionado, por provocar um desperdício de oportunidades ricas de crescimento individual através de experiências de contato. São apresentados alguns rumos possíveis para o ecoturismo no sentido de aproximá-lo dos pressupostos atuais para a educação ambiental dos indivíduos, campo no qual a ousadia para a experimentação passa a ser uma necessidade premente.

PALAVRAS-CHAVE: ecoturismo, educação ambiental, unidades de conservação

ABSTRACT: Thispaperanalyses the relationship between the man and the nature in the contemporary world and the possibilities to develop news values and attitudes in Conservation Units Ecotourism. The way between the intention and the common work very used in this activity, is a question that can cause a waste of opportunities full of individual growth, acquired through the contact

1: Biólogo pela Universidade de São Paulo. Mestreem Psicologia e doutorando em Ciência Ambientalpela Universidade de São Paulo. Diretor Presidente da Physis - Cultura \& Ambiente. Docente do SENAC/SP, Universidade do Grande $\mathrm{ABC}$ e Universidade Anhembi Morumbi.

End.: Rua Vitor Dubugras, 80, apto. 51 - 04114-100 - São Paulo - SP - Tel.: 5575-6001/9195-7685.

E-mail: zysman@physis.org.br

2. Bióloga e Socióloga. Consultora autônoma nas áreas de planejamento, turismo e educação ambiental. Docente do SENAC/SP, Instituto Nacional de Pós-Graduação e da Universidade Anhembi Morumbi. Membro do Instituto de Estud de Complexidadee Pensernosistentico.

E-mail:ritam@dialdata.com.br. experiences. To conclude some possible ways for Ecotourism are shown in order to bring people closer to the actual Environment Education.

KEYWORDS: ecotourism, environment education, conservation units.

\section{Visitar a Natureza}

As áreas naturais selvagens vêm sendo eliminadas durante toda a história da humanidade. Esse processo intensificou-se violentamente nos últimos séculos. Nesse período, o interesse por elas vem crescendo na medida em que suas extensões vêm diminuindo. Não se trata de um fenômeno cultural isolado. Em todas as regiões do mundo encontramosindivíduos, discursos e instituições preocupados e ativos em relação ao significado e as conseqüências do desaparecimento dos ambientes e das espécies silvestres.

Em nossa sociedade temos muito pouco estímulo para refletir sobre o que fazemos, o que queremos ou o que realmente precisamos. Mas o fluxo natural das coisas vai revelando o que de fato tem importância para nós. O crescimento do número de visitas às áreas naturais nos últimos anos vem possivelmente nos mostrar que, tal como da arte, precisamos do contato com a natureza, com a nossa fonte de vida.

Os contos de fadas testemunham a importância psicológica das florestas para os seres humanos. Simbolizando o inconsciente, elas significam o lugar sombrio, perigoso, que nos faz medo. A representação dos desafios, do enfrentamento do bem e do mal se dá, com enorme frequiência, em todos os povos do mundo, na floresta. A floresta contém, portanto, todos os obstáculos que devemos enfrentar e superar para nos tornarmosreis e rainhas, autores de nossaprópria história pessoal. Que seria de nós se não a tivéssemos, perto ou longe, para nos dar a esperança de um dia nos tornarmos dignos de nossa rica experiência humana? A floresta simboliza o próprio processo de aprendizado da vida. Ela dá sentido às atividades humanas. Ou melhor, ela nos faz questionar o sentido do que fazemos.

Quando entramos em uma área natural quase sempre nos sentimos bem, percebemos que alguma coisa muda. Quanto mais nos aprofundamos nessa relação, nessa intimidade com os elementos naturais, percebemos que ali há uma grande escola que nos proporciona uma das raras oportunidades que temos para realmente evoluir. Quem já teve a experiência de, por exemplo, caminhar por uma mesma trilha diversas vezes pode compreender isso: a cada vez há coisas diferentes que podemos ver ou coisas diferentes em que pensar. A situação nunca se repete, o que nos leva a refletir sobre a constante transformação de tudo. Ao perceber isso percebemos a nós mesmos. 
Desde o Neolítico, com a descoberta da possibilidade de interferência nos processos naturais, domesticação e o cultivo de espécies selvagens, pudemos enfrentar, além do medo do perigo, o desconforto (e medo também) da incerteza de em um dia encontrar alimento e noutro não. O desenvolvimento da agricultura nos proporcionou a garantia de ter suprimentos de forma previsível, a ponto de chegarmos à situação em que nos encontramos hoje, em que podemos ter acesso a alimentos produzidos nos mais diversos ecossistemas do mundo:

E assim fomos humanizando os espaços, protegendo-nos do desconhecido. Hoje só ficamos à vontade em ambientes urbanos ou rurais bem transformados. Mesmo o naturalista mais ousado gosta de voltar para casa e encontrar o espaço com o qual se identifica. Fomos nos acostumando a uma forma de viver afastada dos elementos naturais - ou pelo menos sem consciência deles -, evitando aquilo que aparentemente está contra e que vai a qualquermomento produzir algum mal, atacar, causar doenças ou coisas nesse sentido. Ao humanizarmos os espaços, transformamos a sociedade humana em algo muito centrado em si mesmo, construindo toda uma lógica de um para o outro. Fomos, assim, nos afastando desses medos, dessas descobertas, desses fascínios, que estão de alguma forma ocultos no inconsciente coletivo.

O contato com a natureza oferece uma nova oportunidade de enfrentar essas emoções, as diferenças e os mistérios. Promove o resgate de sentimentos pessoais que foram esquecidos nesse processo de desenvolvimento da nossa sociedade. Vejam os vídeos e programas para televisão sobre a vida selvagem: como eles fascinam as pessoas, sejam crianças ou adultos. Quantos seres nem sabemos que existem. Eles vivem suas vidas completamente indiferentes a nós! Não somos tão importantes assim! Criamos um ambiente humano mais confortável, seguro e adequado para nós, mas a idéia de que somos os seres mais importantes do planeta simplesmente está na nossa concepção. Não quer dizer que o mundo esteja de fato a nosso serviço.

Uma visita a espaços naturais, que reflita sobre essa lógica e a questione, transforma nosso tradicional comportamento indiferente. Ao perceber mais, ampliamos nossa experiência. O tempo mais lento de contemplação ajuda a percepção dos ritmos e da essência das coisas, o que é raro de se poder fazer em ambientes humanos. Usamos muito pouco nossos atributos, como a capacidade de percepção sensorial, a consciência, a intuição, a elaboração dos sentimentos - coisas tão importantes para a vida cotidiana das pessoas, que vão determinar a relação que temos com os outros, com o meio natural, com nosso próprio mundo. Na natureza, isso é mais fácil: ao avistarmos um pássaro, uma lagarta, um roedor, há uma possibilidade de aprimorarmonos como ser humano.

Nos meus retiros espirituais,

descubro certas coisas tão banais,

como estar diante de uma coisa e ficar

horas a fio com ela: bárbara, bela, tela de TV.
Nessa canção, Gilberto Gil nos presenteia com uma bela imagem da importância do olhar com atenção, do novo olhar, da descoberta do que as coisas nos ensinam e que podemos não ser meros consumidores de paisagens. É preciso tornarmo-nos testemunhas e não simples observadores de belos cenários.

A oportunidade de visitar áreas naturais pode reformular nossas relações com esse universo, o que nos leva à rica idéia da criação de unidades de conservação, importantes não só por protegerem as espécies de plantas e animais, como por possibilitarem a atuação direta no processo de transformação individual e, por extensão, da socicdade. No cntanto, o fato de protegermos plantas e animais pode estar contaminado com a concepção de que somos os donos do mundo e temos o poder de decidir sobre o futuro e a dinâmica da naturcza. A existência do ser humano e a forma como ele concebe o uso dos recursos naturais fazem parte dessa dinâmica. Há um caminho natural, que conduzirá a humanidade à sobrevivência ou à extinção, no qual temos um certo poder de interferência. Em caso de extinção, o planetaseguirá seu curso natural, independente da existência de unidades de conservação. O que está em jogo é, no fundo, uma questão ética. Qual o sentido de fazermos o que fazemos?

A preocupação com a preservação ambiental, o sentido de cuidado, é próprio da natureza humana, ou seja, destruição e conservação são processos que serão assimilados pelo funcionamento dos ecossistemas, independentemente de ficarmos chateados ou felizes. Se o mico-leão dourado ou as baleias se extinguiram, outros virão, assim como tantos outros já desapareceram, e o mundo continua.

A ética e a estética são duas invenções humanas que explicam o anseio pela preservação. Só sobrevivemos em função do afeto que temos pelo outro e que origina a preocupação com os filhos, com os descendentes, com os companheiros de sociedade, com os membros da tribo. Esse afeto, o gostar do outro, produz um "efeito colateral" de gostar de coisas em geral, da natureza. Não jogar lixo numa trilha, em últimainstância, é um hábito derivado do caráter de apreciação estética da paisagcm, uma vez que boa parte dos materiais jogadosé inócua; apenas são desconhecidos da natureza e não são a ela reintegrados. Mas produz um efeito que incomoda os quc apreciam a natureza tal como ela é. O afeto que temos pelos elementos naturais traz a preocupação com os animais e as plantas, fazendo com que algumas pessoas canalizem esse sentimento de cuidado e adotem-no como causa, dedicandoboa parte do tempo de suas vidas na batalha pela sua preservação.

Esse afeto, num mundo com 6 bilhões de pessoas, funciona de forma diferente do que sempre foi quando éramos pequenos grupos. Estamos perplexos em face da complexidade do mundo em que vivemos, onde somos tratados, muitas vezes, apenas como um número. Isso pode dar uma sensação de impotência, pois o que está além do pequeno contexto perceptível de cada indivíduo fica fora de sua compreensão e, portanto, de seu espectro de ação. Cada um é direcionado para cuidar de sua própria vida, subtraindo-se do sentido de participação coletiva.

A experiência de estar na naturcza pode ser um grande laboratório para a reformulação da questão da individualidade/individualismo nos processos colctivos: não sabemos que experiência poderia ser melhor do que essa para as pessoas se reumanizarem. O espaço natural pode ser visto como uma necessidade vital sem o 
qual não se pode evoluir. Assim, ele deixa de ter apenas valor utilitário e passa a ter valor existencial. Se ele precisa existir para que eu também exista, devo ter cuidados com ele sem esperar algo em troca e criar uma perspectiva para atividades como 0 ecoturismo, diferente das que existem hoje.

\section{Desenvolvimento}

O ecoturismo em unidades de conservação tem se mostrado um interessante meio para possibilitar o contato mais íntimo entre indivíduo e natureza. Discutiremos, a seguir, as implicações desse processo, o papel do ecoturismo e as novas possibilidades profissionais para a conservação de recursos naturais.

\section{Unidades de Conservação como Espaços de Reencontro}

Para as pessoas que possuem ligação pessoal muito forte com a natureza, fica difícil racionalizar sobre as diferentes percepções que o contato com cada elemento natural proporciona, quer seja uma particularidade (uma planta, um inseto ou uma cachoeira), quer seja o ecossistema inteiro. A ligação afetiva, emotiva, espiritual, ou como queiram chamar, leva a uma busca pessoal por espaços que proporcionem o bem-estar inerente a essas situações interativas.

A simples suposição da inexistência de áreas preservadas nos faz refletir sobre a sensação de vazio que a humanidade viveria caso esses espaços não existissem. A sociedade contemporânea, como se encontra organizada, é quase sempre carente do contato direto com a natureza. É privada, portanto, das oportunidades de vivências pessoais e de crescimento espiritual decorrentes desse contato.

Assim sendo, os critérios para a criação de unidades de conservação devem ter como prioridade a possibilidade de proporcionar experiências pessoais para a humanidade. Antes da visão econômica ou utilitária dos recursos naturais, devem transmitir a tranqüilidade de simplesmente sabermos que elas existem, que estão bem e, que quando quisermos, podemos visitá-las ciente de que esta e as futuras gerações têm e terão a possibilidade de ter experiências diretas.

No entanto, dentro da lógica da nossa sociedade capitalista no final do século $\mathrm{XX}$, as justificativas para a criação de unidades de conservação têm sido outras. Mais importa a garantia de preservação da biodiversidade pelo seu caráter utilitário e potencial em futuras descobertas de novos remédios, alimentos ou matérias-primas, uma espécie de banco onde estão depositadas as riquezas do futuro.

O movimento ambientalista, intensificado a partir da década de 60, popularizou a mentalidade preservacionista que defendia a exclusão das atividades humanas em certas áreas naturais para evitar o impacto inerente a elas. Mais recentemente, talvez como incorporação da lógica neoliberal de um mundo globalizado, defende- se a possibilidade de "uso racional", "sustentável", dos recursos naturais. Assim, as chamadas zonas intangíveis das unidades de conservação passam a ser vistas com outro enfoque: o da utilização sustentável dos organismos ali preservados. Há de fato compatibilidade entre preservação e utilização?

Para explicar a sustentabilidade, os argumentos são estritamente técnicos, embasados na confiança da superação de problemas através do conhecimento científico. Assim pode-se calcular quantas árvores pode-se cortar para fazer um manejo florestal ou quantos animais pode-se abater para garantir a estabilidade de uma população. Nunca se admite outras lógicas para a existência dos espaços naturais, o fato de que eles têm que simplesmente existir por existir, por uma questão espiritual, ética ou mítica, e não pela simples contabilização de quanto dinheiro nos dará no futuro.

Além disso, a criação de um sistema de unidades de conservação não é garantia suficiente de que existirão, no futuro, ecossistemas viáveis até mesmo do ponto de vista utilitário. As unidades de conservação, que teoricamente são criadas para a proteção, trazem embutidas uma lógica perversa que autoriza a destruição das áreas não preservadas. Imaginem o mapa do Brasil com manchas demarcando os parques que já existem e façam uma viagem no tempo para daqui a mil anos ou dois mil anos. Se elas de fato cumprirem o seu papel teremos uma amostragem do que um dia foi a natureza brasileira, mas, se o ritmo de ocupação das áreas não protegidas se mantiver, os demais espaços, aqueles que ficaram fora das unidades de conservação, estarão completamente transformados pela ação humana, pois ali será implementado o "desenvolvimento" do país. Essas unidades de conservação não passarão de sombras de um passado exuberante. Hoje, quando olhamos o mapa e vemos que há uma maravilhosa área verde ocupando todo o lado norte da América do Sul, fica difícil supormos que ela ficará reduzida a pequenas manchas, preservadas com tanto "zelo".

Muitas unidades de conservação foram definidas em função da existência de atrativos exuberantes, como a presença de cataratas, abismos, cavernas, rios ou marcos históricos. Raras vezesconsideram-se fatores como a importância ecológica, a existência de espécies endêmicas ou ameaçadas, valor mitológico ou afetivo para comunidades tradicionais etc. Mal se descreveu as espécies existentes nos ecossistemas naturais, como decidir que aqui, e não ali, deve ser preservado?

Pensando de outra forma, podemos questionar se temos o direito de destruir aquilo que não temos capacidade de criar. Pode-se destruir a cidade para a criação de sistemas mais modernos que superam os antigos, novas relações sociais, afetivas etc., pois esse é o nosso domínio. Mas não sabemos recriar a natureza e daí o desejo de zelar, de proteger. Nenhum animal ou planta, de fato, está pensando em recriar ou em destruir. Os seres humanos é que precisam refletir sobre a destruição que produzem, pela responsabilidade de possuírem consciência e por terem relativa clareza das conseqüências de seus atos para a sua própria existência. Temos um poder de destruição muito maior do que qualquer outra espécie já teve, e a nossa consciência nos dá a possibilidade de pensar sobre isso. Então, porque não refletir dentro de uma nova lógica, que possibilite desenvolver uma relação harmoniosa de 
todos os seres sobreviverem juntos, numa caminhada coletiva, como companheiros de planeta?

No Brasil, as unidades de conservação têm sido criadas sem as mínimas condições para garantir a sua conservação: não há recursos humanos, planos de manejo, previsão orçamentária para investimentos em equipamentos e outras necessidades. Pouquíssimas possuem estrutura mínima para se manterem em funcionamento, e a maioria encontra-se abandonada ou delimitada apenas no papel. Para a criação de áreas protegidas, há que se propor uma política pública ou privada de gestão das já existentes, para que elas possam de fato cumprir as metas que, pelo menos temporariamente, são determinadas e traçadas para elas.

É necessário que todos os setores da sociedade - o movimento ambientalista, os empresários interessados nas atividades em parques (como o ecoturismo), os administradores - discutam muito sobre os destinos dessas áreas, perante nova lógica coletiva de conservação, que não se restrinja à ação do poder público, uma vez que os recursos têm sido escassos para esse setor. O Brasil tem criado unidades de conservação como forma paliativa de garantir a preservação de ecossistemas até que outras prioridades, como o pagamento da dívida externa, a competitividade da moeda no mercado internacional, a balança comercial etc. sejam resolvidas. O mais cruel é que a visão econômica não coloca em primeiro plano as pessoas, tampouco a natureza. Os projetos educacionais, sociais e ambientais são sempre relegados para um segundo momento, pois a lógica de mercado mundial exige do Brasil uma postura voltada para a economia. Quando a política econômica estiver estável, quando o país estiver em pleno desenvolvimento, quando o PIB crescer, quando formos, enfim, um país rico, então será possível investirmos em preservação, em educação e em questões humanitárias. Não há fórmula melhor para a geração do espírito individualista, materialista, consumista e competitivo do cidadão contemporâneo.

As visitas a uma área preservada, diante desta realidade, deveriam obrigatoriamente favorecer experiências educativas e de questionamento desses valores, independente dos tipos de visão que o visitante já possua sobre as questões ambientais. Os que já têm consciência sobre a importância da natureza, trabalham há muito tempo com ela, têm amor pelo que fazem, devem desenvolver atividades diferentes daqueles que jogam lixo pela janela do carro e estão visitando-a pela primeira vez. No entanto, todas elas têm que proporcionar vivências transformadoras, que possam acrescentar algo na vida do indivíduo. Sempre as unidades de conservação devem estar organizadas para atender a públicos diferentes, conhecendo bem o seu perfil e tomando atitudes mais interativas entre os funcionários, a área e o visitante, através da elaboração de novos programas de visitação pública, menos punitivos e mais integradores. Porque a grande maravilha, a verdadeira "mina de ouro", é a experiência pessoal que se tem no contato com a natureza. Essa experiência não é transferível. Ela é de uma amplitude tal que não se pode traduzi-la em palavras.

Infelizmente, no entanto, a visitação aos espaços preservados não é acessível a todos, e só quem tem recursos financeiros para se deslocar até eles é que pode conhecê-los. O ecoturismo ainda é uma atividade restritiva.

\section{Ecoturismo e sua połencialidade}

O setor de ecoturismo, definido muito recentemente, se propõe a possibilitar o contato dos indivíduos com os espaços naturais, de modo a garantir a esses últimos sustentabilidade econômica e ecológica.

Uma das principais definições, a da The Ecotourism Society diz o seguinte:

Ecoturismo é a visita responsável a áreas naturais, visando preservar o meio ambiente e

o bem-estar das populaçōes locais (Lindberg \& Hawkins, 1996).

A partir daí pode-se depreender que o ecoturismo surgiu como um meio de alcançar o desenvolvimento sustentável das regiões que ainda hoje apresentam importantes conjuntos naturais, de grande valor ecológico e paisagístico e como estratégia de conservação de culturas tradicionais. Portanto, ecoturismo não contém um fim em si, não existe para desenvolver-se a si mesmo, mas sim para possibilitar a inserção destas ditas regiões que, comumente, foram afastadas do desenvolvimento regional.

Observa-se ainda que nessas áreas, as populações residentes possuem um forte vínculo com a natureza, que representa o suporte principal de sua caracterização cultural. Daí a preocupação, na definição de ecoturismo, de promover o bem estar dessas populações. Por "bem-estar" compreende-se sua integração ao processo de desenvolvimento econômico sem corromper suas características culturais mais profundas. Afinal, se estes povos ainda vivem tendo a natureza como suporte para a manutenção de suas culturas, possivelmente são os únicos a realmente conhecer as formas de sustentabilidade específica daqueles ambientes.

As instituições brasileiras voltadas para a organização e execução das atividades ecoturísticas foram se estruturando a partir de um outro histórico e possuem hoje um caráter empresarial. Sendo assim, funcionam dentro da lógica do mercado e priorizam os aspectos voltados à prestação de serviços e ao retorno econômico em detrimento das prioridades conservacionistas.

Ao contrário de algumas ONGs que trabalham com ecoturismo e inclusive vêm ganhando prêmios por suas iniciativas no setor, as empresas têm muito raramente dedicado atenção especial a um trabalho educativo elaborado a partir de pressupostos inovadores. Costumam supor que o simples contato com a natureza já é algo suficientemente excepcional para garantir a mudança de comportamento dos indivíduos. As prioridades de conservação da natureza e das culturas locais não vêm sendo minimamente atendidas pelo vertiginoso crescimento dessa atividade. $\mathrm{Na}$ experiência prática, o potencial transformador, que o contato direto com a natureza pode proporcionar, tem sido desperdiçado.

Entrar em contato com milhares de outros seres vivos é algo exótico para nós. Sem dúvida é um momento particular de nossa existência, uma vez que pouca pessoas de nossa sociedade vivem imersas em um ambiente de rica biodiversidade. 
A conotação de exótico vem do desconhecimento daqueles elementos todos. Mesmo sabendo o nome científico de algumas espécies conheccmos muito pouco de sua natureza, de sua experiência, de suas características.

Além disso, como dissemos, caminhar por espaços selvagens nos traz a oportunidade de enfrentar dificuldades, de superar limitações, como os de ter que dar grandes saltos, caminhar por espaços estreitos ou à beira de desfiladeiros, esperar uma cobra abrir o caminho, atravessar rios, etc. Nesses enfrentamentos somos levados a conhecer melhor a nós mesmos. Afinal, sem nunca termos passado por essas experiências antes, como sabermos de nossas reações diante delas? Podemos aproveitar para conhecer melhor nossos corpos e nossas emoções. Na maioria das vezes, nossas reações no campo são muito diferentes daquelas que imaginávamos antes de enfrentar certas situações. Nessas travessias - que ninguém deve fazcr sozinho - estabelecemos também novas relações sociais, pois muitas vezes precisamos ajudar o outro e sermos ajudados. As experiências do companheirismo e da solidariedade podem ser praticadas, sedimentadas, aprofundadas. Aprendemos a confiar nos companheiros de viagem.

A percepção da interdependência e da complementaridade que temos uns com os outros nos relembra sermos membros de uma grande teia, enorme e complexa em suas relações, desfazendo as hierarquias a que estamos acostumados. Ao passarmos por situações as mais variadas, temos que aceitar as limitações de cada situação, nos submeter às vicissitudes da natureza, estar abertos ao imprevisto, superar nossas barreiras e entrar em contato direto com a água e com a terra.

Podemos, se nos permitirmos, questionar nossos valores, aprender com a experiência, e voltar para casa renovados e enriquecidos, capazes de buscar reformulações para os aspectos indesejáveis de nossa vida cotidiana. Numa viagem de ecoturismo podemos questionar sobre o que é de fato necessidade, segurança e conforto. Um viajante aplicado pode surpreender-se com suas próprias respostas..

Nossos valores sobre conforto, por exemplo, são compatíveis com os da comunidade que estamos visitando? O visitante deverá trazer sua cultura ou tentar integrar-se aos hábitos locais? Quais os limites do contato entre culturas? Existem? Uma exigência de conforto e segurança do visitante pode ofender os hábitos locais? O ecoturista está buscando afirmar sua própria cultura (será que precisamos?) ou conhecer de fato o diferente? Como estar aberto para essas experiências?

Pelo nosso condicionamento cultural podemos exigir certo padrão de conforto e segurança; mas é preciso tomar cuidado para que isso não encubra o medo de experimentar outras possibilidades de viver e de pensar. É preciso que o ecoturismo deixe de "preparar" os locais para receber o visitante e passe a preparar o visitante para conhecer os locais. O ecoturista que for educado a compreender e conviver com a diferença saberá reconhecer a riqueza dessa experiência.

Muitas vezes, um atendimento comumente considerado como "de qualidade" pode tornar a experiência do visitante totalmente previsível. Uma pousada com televisão e frigobar no quarto, um guia supertreinado, bem vestido e bem equipado, constituem serviços de qualidade como se espera que sejam, em qualquer lugar. Mas, se o visitante não sabe o que significa entrar em contato com a alma do lugar fica sem poder desejar essa experiência.

O grande mitólogo Joseph Campbell certa vez deu o seguinte conselho a uma senhora que havia planejado minuciosamente sua viagem à Grécia, em busca do contato com as divindades:

Tomara que tudo saia diferente do que a senhora planejou. Como espera que os deuses vão encontrá-la se está fazendo tudo ao seu alcance para impedir que eles a encontrem? A menos que deixe espaço para o imprevisto, como pode o divino entrar em você? 0 começo da aventura de encontrar a si mesmo está em perder o caminho ${ }^{3}$.

Se apenas voltar para casa com mais um conjunto de belas fotos ou mais um banho de cachoeira, não estará faltando alguma coisa? É claro que isso já é bastante bom, mas estamos nos referindo a um potencial, ao universo a que a natureza nos remete. Os lugares - todos - têm uma alma, que anseia por ser percebida, sentida e mestiçada à do visitante.

Sem a atuação educadora de todos os profissionais envolvidos com o ecoturismo, fica mais difícil vislumbrarmos importantes processos de mudança. Nossa experiência cultural nos leva a consumir paisagens, a listar os atrativos a serem visitados e a cancelá-los à medida que passamos por eles. O ecoturista costuma ter em seu cômputo geral "quantos" lugares já conheceu e qual será o "próximo" roteiro que irá fazer. Procura novos destinos nas agências que conhece. E menos comum encontrar alguém que queira voltar a um lugar por lá ter tido boas experiências e desejar ampliá-las.

A lógica de descoberta de novos roteiros, de novos lugares, acaba sendo a mesma lógica do consumo do supermercado. Quer dizer: consome-se paisagens e não se tem uma experiência pessoal e diferente. Claro que essas observações não podem ser generalizadas, pois muitos têm experiências intensas e enriquecedoras. Estamos falando sobre a lógica mais comum dos ecoturistas, das agências e das pessoas que trabalham com ecoturismo e da maneira como ele está se desenvolvendo.

Esse espírito não está isolado da tendência geral de nossa sociedade, mas devemos alertar para o fato do ecoturismo poder se tornar uma atividade com dinâmica própria, capaz de proporcionar experiências de resgate muito significativas para os indivíduos e para a sociedade, e que esse enorme potencial pode estar sendo desperdiçado. Pensando assim, acreditamos que o ecoturismo não pode ser reduzido à retórica do desenvolvimento sustentável. É esse o ponto. 


\section{Conclusāo}

A realidade costuma ser mais complexa do que os esquemas que propomos para compreender e organizar as nossas atividades. Dentro do que chamamos de ecoturismo existe um mosaico bastante diversificado de propostas e de experiências. Há agências que promovem visitas a natureza como uma opção a mais para seus clientes, portanto encarando o setor como mais uma modalidade do turismo convencional. Outras, em diferentes graus, estão preocupadas com a conservação dos espaços que vão visitar.

As visitas a natureza não são obviamente uma novidade, uma vezque sempre existiram. Apenas agora estamos organizando-as como negócio e, assim, tornandoas mais acessíveis a um público mais amplo. Essas visitas podem ser sempre muito enriquecedoras, aliás, como qualquer viagem. Mas somos levados a desejar que essa experiência seja potencializada perante a raridade dos espaços naturais preservados, a sua fragilidade e o fato de serem pouco valorizados em nossa sociedade.

Por ter surgido como um negócio, o setor ecoturístico não se propôs, ainda, a refletir sobre o que faz. Produz viagens e não prioritariamente experiências, nem conhecimento. Só reproduz estratégias de marketing e conceitos administrativos convencionais, aplicados tradicionalmente a outras áreas do conhecimento humano.

Há que se criar uma "rede" com identidade própria, formada por grupos de estudo, ONGs, agências, pessoas preocupadas em experimentar situações inovadoras. Não vamos todos encontrar um mesmo caminho, nem compartilhar a mesma opinião, evidentemente, mas podemos conviver com a aceitação da diversidade aliás, lição número um da ecologia - e compartilhar um código de ética, que una a todos.

Isso não só é oportuno pela experiência em si, como se mostra necessário e urgente, na medida em que vemos crescer, com uma velocidade muito grande, o consumo irresponsável das paisagens, das trilhas e das cachoeiras, e uma padronização chocante dos meios de hospedagem e da infra-estrutura ecoturística, mesmo nos lugares onde a personalidade da cultura local é forte e expressiva. Hoje é perfeitamente possível hospedar-se em uma pequena pousada de um vilarejo da Bahia com o mesmo padrão de outra em Goiás ou no Maranhão. Quem está induzindo esse processo? Onde fica a proposta de respeito e valorização das culturas locais? Nos eventos folclóricos pré-programados? No sotaque do garçom? Porque se definiu que o ecoturista precisa de televisão e frigobar no quarto? Isso é compatível com os valores e estética local? A idéia inflexível de padrão de qualidade põe seriamente em risco os valores locais que, contraditoriamente, o ecoturismo propõe resgatar.

Se a própria população local está construindo pousadas e formando guias pelo viés do visitante, ela está fazendo ecoturismo de uma forma diferente da sua estética e lógica próprias, diminuindo a possibilidade de experiência do turista.

O ecoturismo torna-se, assim, infelizmente, o próprio exemplo da fábula do lobo em pele de cordeiro. Pior: o faz de uma maneira ingênua, uma vez que o setor até acredita que está de fato contribuindo para os processos conservacionistas. As pressões mercadológicas são tão intensas que os profissionais da área acabam abrindo uma série de concessões para poderem continuar competitivos, modificando seus próprios princípios e diminuindo suas possibilidades de livre atuação. Isso reforça ainda mais a necessidade dessas reflexões e da criação de uma rede de troca e colaboração entre os diferentes segmentos.

Estamos nos aproximando de questões difíceis de serem levantadas. O que de fato move uma pessoa com desejo de contribuir na conservação da natureza? A resposta, há tanto experimentada e comprovada pelos que têm trabalhado na área, é a afetividade. Como incluir esse "elemento" nos debates técnicos? Se já colecionamos uma lista infindável de argumentos - na forma de leis, tratados, convenções, teses, e arti-gos sobre a importância da conservação - porque as coisas são tão difíceis de mudar?

O professor Joseph Cornell (1997) tem dito e comprovado em seus livros, workshops e conferências no mundo todo que somente a descoberta e o desenvolvimento da afetividade pode transformar a experiência humana e conseqüentemente nossa relação com os elementos naturais. Podemos saber tudo sobre a natureza, mas isso não é suficiente para querermos preservá-la. Para preservarmos temos que ter com a natureza uma relação afetiva, de amor, que gera o desejo de que ela continue existindo. $\mathrm{O}$ amor é o que dá um sentido maior às coisas. Mas isso é algo muito delicado de se introduzir nesse mundo objetivo, ou melhor, pretensamente objetivo.

Quem tem trabalhado com ecoturismo nesta ótica sabe de seu potencial para lidar com tal abordagem. A oportunidade de ter uma experiência direta com outras formas de vida é algo muito mais transformador do que qualquer proposta bem elaborada de planejamento sustentável. O ecoturismo deve se assumircomo um setor da sociedade capaz de transformar e, com isso, contribuir para uma mudança de paradigma. Só ainda não tem uma percepção consciente dessa possibilidade, não se vê desejoso de transformar. Está aturdido em face das pressões do mercado.

É preciso ter a liberdade de criar, de experimentar, perder algumas oportunidades, criar outras. Um curso sobre elaboração de roteiros pode fornecer as instruções básicas, mas não existe um meio único ou mais correto de conduzir um ecoturista para o "meio do mato". O profissional, dentro de sua responsabilidade, deve se permitir ouvir sua intuição pessoal, sua experiência e experimentar, trocar com os outros seus resultados positivos e negativos. Não só executar a atividade, mas investigar, pesquisar, buscar soluções e alternativas com criatividade, imaginação, intuição. Construir, enfim, e não só buscar capacidade técnica, competência, porque isso é fácil. Você faz uma universidade ou um curso profissionalizante e conquista competência técnica. Adquirir habilidades é fácil em ecoturismo. Aprofundar-se na atividade já não é tão evidente. Quando experimentamos atividades com grupos, devemos ter claro que há muitos parâmetros em questão, tais como os relacionados à ecologia, psicologia, filosofia, artes etc.

Os profissionais tornaram-se técnicos. Não são leitores, reflexivos, não "vão atrás", quando isso seria absolutamente fundamental. Como em tantos outros setores, a teoria está desvinculada da prática. Mas sabemos que não é necessário que 
seja assim. Podemos criar um fluxo permanente entre as idéias e as ações, promovendo assim o desenvolvimento construtivo do ecoturismo no Brasil.

\section{Referências Bibliográficas}

CORNELL, J. 1997. A alegria de aprender com a natureza. Sāo Paulo: SENAC/Melhoramentos COUSINEAU, P. 1999. A arte da peregrinação. Sảo Paulo: Ágora.

LINDBERG, K. \& HAWKINS, D. E. 1996. Ecoturismo: guia para planejamento e gestão. Sāo Paulo: SENAC.

Recebido em 19/10/00

Aprovado em 17/11/00 